\title{
The Soul of Therapy: The Therapist's Use of Self in the Therapeutic Relationship
}

\author{
Harry Joseph Aponte ${ }^{1}$ (D)
}

Accepted: 13 October 2021 / Published online: 22 October 2021

(c) The Author(s) 2021

\begin{abstract}
This paper is based on the premises that the conscious, active and purposeful use of self by the therapist in the therapeutic process is an essential aptitude in establishing an effective therapeutic relationship, and that this therapeutically purposeful use of self can and should be incorporated in the training of all therapists in a explicitly systematic manner. The paper will attempt to identify the contributions of the "what and how" the use of self by therapists contributes to the therapeutic process. First of all, therapists' use of self is meant to be viewed as a Common Factor as defined by Sprenkle, Davis \& Lebow (2009), which is a perspective about the effectiveness of therapy that "asserts that the qualities and capabilities of the person offering the treatment are more important than the treatment itself" (p. 4). Secondly, the use of self by therapists emphasizes developing the skill set of the therapist in the conscious, active and purposeful use of self as is in the moment of the therapeutic engagement with clients, and does so without denying the importance of therapists working to resolve personal issues of theirs that may interfere with the therapist's professional effectiveness. Therapists' use of self gives particular emphasis to the purposeful use of self as is in therapy's relationship, assessment and interventions whatever the therapy model (Aponte \& Kissil, 2016). Thirdly, the use of self represents an aptitude that can be developed and refined through well elaborated structures for schooling therapists in the therapeutic use of all they bring of their personal selves to the therapy relationship including through the use of their human vulnerabilities as they exist at the moment of empathic engagement with clients.
\end{abstract}

Keywords Use of self · Countertransference · Training therapists on use of self · Person of the therapist

\section{Introduction}

The personal self who is the therapist is an essential element of the therapeutic process, because it is the human relationship with clients that is the medium through which the work of therapy is done. There is a strong argument that it is the therapist and not the therapy model per se that is more influential in the outcome of the therapeutic process (Blow et al., 2007). It is evident there has been in the field growing emphasis on training therapists on the conscious and strategic use of their personal selves as apparent from recent research and literature on the subject (Aponte, 1994b; Aponte \& Winter, 2000; Aponte \& Kissil, 2016: D'Aniello \& Fife, 2020; Satir, 2000; Simon, 2006; Simon, 2012; Wampold \& Imel, 2015; Niño, Kissil \& Apolinar Claudio,

Harry Joseph Aponte

harryjaponte@verizon.net

1 Private Practice, Philadelphia, PA, USA
2015). What follows will illustrate through an analysis of one approach to the training of therapists on the use of self in therapy (the Person-of-the-Therapist Training model) to highlight some components that are meant to maximize a therapist's potential effectiveness regardless of therapy model.

Self-awareness and self-mastery of the person in the context of the therapeutic process is the primary goal of training within the POTT model (Aponte, 2017). The POTT concept was originally introduced (Aponte, 1982; Aponte \& Winter, 1987; Aponte, 1992; Aponte, etc., 2009) as an approach to training therapists in the purposeful use of their "selves" irrespective of their adherence to a specific therapy model with particular emphasis on working through the therapist's own human vulnerability. This is in line with Sprenkle and Blow's assertion (2004b) that:

We believe that there is compelling evidence that the largest part of the variance in successful psychotherapy is due to factors that are not unique to specific therapy models. 
Self-awareness and self-mastery in the POTT model contrasts with the use of those terms by others, like Sigmund Freud, who put it in terms of therapists needing to undergo their own psychoanalysis to be conscious of and work on removing the "obstacle" (Bochner, p. 1) to their therapy of their own unresolved emotional problems, and Virginia Satir who spoke of being "in touch with myself becoming a more integrated self" in order "to make greater contact with the other person (Satir, p. 24). The POTT model emphasizes less self-resolution and more the capacity in the moment of therapeutic engagement with clients by achieving consciousness of their own related personal struggles and vulnerabilities to be able to resonate and empathize with the pains and issues of their clients. This promotes more intimate insight in the moment into what clients are experiencing, as well as facilitates greater intuition into the dynamics of the experiences of their clients at the present moment of connection with the client in the therapeutic process.

The POTT philosophy accepts the generally accepted principle about the importance of self-work approaches that focus on therapists pursuing resolution of their personal issues which are viewed as potentially toxic to the therapeutic process (Bochner, 2000; Bowen, 1972; Kerr, 1981; Satir, 2000). However, the POTT viewpoint is distinctive in that it prioritizes working through the active use of "self as $i s$ " at the moment of contact with clients. Clients encounter the therapist as is in the present, not the person the therapist aspires to be tomorrow after further training or personal therapy. Therapists engage as they are at that moment of engagement-not only with their assets, but also with their personal issues, such as fear of being vulnerable, needing to be in control, lack of self-confidence (Aponte \& Kissil, 2014). Within this framework, the challenge in training therapists is to prepare them to work with and through who they are at the clinical moment so as to enhance the effectiveness of the therapist's technical tools at that time. In this spirit therapists as "wounded healers" (Nouwen, 1972; Aponte, 2002) work empathically with and through that common human woundedness to relate to, understand and intervene with their clients. At its core, the POTT model looks to bridge the work on self with the work of therapy as it is played out in the "now moment" of the therapeutic process.

Moreover, the POTT perspective also goes beyond the psychology of the self so as to include the significance of personal values, culture and spirituality in therapy, as well as the social forces in therapists' lives - their gender, lifestyles, race, ethnicity, and social location (Aponte, 1985; Aponte, 1991; Aponte, 1994a; Aponte, 1996; Aponte, 1998; Aponte, 2002; Aponte, 2009a; Aponte \& Mendez, 2014; Aponte \& Nelson, 2018). It incorporates a concern for the cultural and spiritual dimensions of peoples' personal functioning (Aponte, ), and the sociopolitical influences that are active factors in therapists' and in their clients' lives, particularly those that marginalize people because of race, culture and socioeconomic status (Falicov, 2009; Lappin \& Hardy, 1997; McDowell \& Shelton, 2002). This paper strives to operationalize specifically the underlying philosophy of a "self" training model, expanding and adding to Sprenkle et al.'s premise that use of self within the intimate relational process of therapy is foundational to the training of psychotherapists.

\section{Common Factors}

The common factors approach to therapy schools continues to gain considerable attention in the psychotherapy field (Sprenkle, D. H. \& Blow, A. J., 2004a; Sprenkle, D H., Davis, S. D. \& Lebow, J. L., 2009; Simon, 2006). Its central premise is summed up as follows:

In brief, this paradigm suggests that psychotherapy works predominantly not because of the unique contributions of any particular model of therapy or unique set of interventions (what we call the model-driven change paradigm) but rather because of a set of common factors or mechanisms of change that cuts across all effective therapies. (Sprenkle, D. H., Davis, S. D., \& Lebow, J. L., 2009, p. 2)

This thinking does not restrict the power of change to a particular model of therapy, and attempts to identify various common factors that influence the course and effectiveness of therapy whatever the model. Therapists' use of their personal self in their work is just one such factor. The POTT perspective about both the personal humanity and social location in society of the therapist is such a factor, which includes the spiritual, philosophical, cultural, and socio-political dynamics of society, which are all relevant to the therapeutic process, and we believe are particularly critical factors in today's varied, conflictual and disjointed philosophical aspects of our society. Moreover, the POTT stance aims to facilitate an integrative approach to therapy by identifying a cohesive core of the therapist's personal processes common to all models of therapy along with the complex psycho-social context in which we live.

Sprenkle and Blow (2004a, p. 114) point to the "expanded therapeutic alliance," namely the therapist with the family and subsystems of the family, as being a "unique" common factor to Marriage and Family Therapy. This puts the therapist in more complex relationships than the one-to-one relationship of individual therapy. Also, they point to how, "attention has shifted to the therapeutic alliance, which, by definition, is the joint product of the therapist and client together," (p. 122). They speak of how "the therapeutic relationship is the common factor most studied in MFT research," (p. 122). The research according to this article speaks to how the "relationship skills" of the therapist are 
"a widely valued component of common factors," (p. 123). From our perspective this is a compelling argument for strengthening the training component of therapist's use of self, which we believe should include psycho-social-political context of society in the preparation of psychotherapists in our field.

Indeed, the influence of what therapists bring of their personal selves to the therapy process has been there from the beginning of talking therapy in the early 1900's when Freud identified the therapist's countertransference, an unconscious projection of the therapist's personal issues onto the therapeutic process, something that he considered problematic and called for work to root out these personal toxic elements through the therapist's own training psychoanalysis (Freud, 1964). Theodore Reik (1948) spoke in the 1940's about listening with the "third ear," a form of self-awareness through which therapists can be sensitive to and aware of what patients communicate through therapists' inner experience of their own person while engaged in the therapeutic process with the patient-meaning that this third ear "listens" to the patient by expanding their listening to include therapists' own inner experiences and reactions to their patients. From this perspective therapists' countertransference could potentially be utilized as a helpful therapeutic instrument. In the 1960's Otto Kernberg (Bochner, 2000, p. 117) coined the term totalistic countertransference, referring to the "total emotional reaction of the psychoanalyst to the patient," a concept that had been anticipated by the objectrelations theorist, Donald Winnicott. Again, this was a move toward taking a constructive view of what therapists bring of their psychological selves to the therapeutic relationship, something to be aware of and use as a therapeutic tool.

Fast forward to the systemic perspectives of Murray Bowen (1972) and Virginia Satir (2000) who brought this interest in therapists' self-awareness into the family therapy world and incorporated it as cornerstones of their training and formation of therapists to do therapy. Their training models emphasized not only therapist self-awareness, but also therapists finding healing of self within the contexts of their families of origin. Both viewed therapists' reaching higher resolution of their own family issues as potentially directly impacting the effectiveness of their therapy.

Logically, the study by Joan Cook, Tatyana Biyanova, Jon Elhai, Paula Schnurr and James Coyne (2010), found that their relationship-oriented common-factor techniques are "what clinicians believe are the most important mechanisms that facilitate patient improvement in psychotherapy" (p. 265). Norcross and Wampold themselves concluded, from a task force on evidence-based therapy relationships that "adapting or tailoring the therapy relationship to specific patient characteristics (in addition to diagnosis) enhances the effectiveness of treatment" (2011). Simon (2006, p. 343) brings this whole debate about therapy models versus the person of the therapist as a common factor to a more personal level for the therapist by proposing that "the route to maximum effectiveness for any therapist is to experience the therapy that he or she does as being 'his' or 'her' therapy, a mechanism for self-expression of his or her deeply held view of the human condition." In any case, systemic theorists have made the interactive and interdependent relationship between therapist and client central to their concept of a healing therapeutic experience for their clients.

So, what is distinctive within the common factors perspectives of today's systemic theorists about the training of therapists in the Person-of-the-Therapist Model of Training? In training, rather than giving primary emphasis to therapists healing their emotional wounds, its primary emphasis has to do with mastering the use of self with particular attunement to therapists' own emotional vulnerabilities in the therapeutic engagement with clients so as to potentiate now moment therapists' technical skills in forming a therapeutic relationship with clients that facilitates a more comprehensive assessment and more effective interventions. This approach reflects a view that highlights what therapists purposefully bring of their trained personal selves by adding depth and resonance to their technical training in the therapeutic process. Various systemic thinkers from a variety of different models of therapy have reflected the importance of this potential within the therapeutic process (Bennett-Levy, J., 2005), something this paper views as recognizing a common factor within talking therapies.

For example, to quote Salvador Minuchin of recent history (2017, p. 37):

In 1975, when I wrote "Families and Family Therapy"... I thought that all therapists needed to do to translate their interest in understanding families into becoming effective therapists was to develop an alphabet of skills... But as I got more experience training therapists to use these techniques, it became clear that the techniques by themselves weren't all that useful. It was therapists themselves who were the instruments of change.

Sprenkle and associates (2009, p. 4) have stated:

The qualities and capabilities of the person offering the treatment are more important than the treatment itself.

Carl Rogers (1961, p. 44) puts it this way:

It is the attitudes and feelings of the therapist, rather than his theoretical orientation, which is important. Virginia Satir's words (2000, p.26):

Can we accept as a given that the self of the therapist is an essential factor in the therapeutic process?

\section{Training Therapists in Their Therapeutic Use of Self}

Even where there is agreement about the potential positive value in what the self of the therapist can bring to the 
conduct of therapy, there are differing emphases in the field about the goals and methods offered in the training of that "self" of the therapist. Traditionally most of it is to help therapists resolve their personal issues to prevent harm to clients, while also aiming to free therapists to use themselves with more sensitivity, empathy and insight when they work with clients.

Edward Titchener (1909) was first to coin the word "empathy" in the context of how therapists relate to their patients, which referred essentially to feeling with your patient. Yet, the question remains how does one actually train therapists to feel with clients or in other words to share in their clients' experiences? Of course, this very much depends on the goals of the training of the self.

Leading figures of our field repeatedly speak of the necessity of being present with the client (Sude, M. E. \& Gambrel, L. E., 2016). Satir (p. 24), for example, states:

I have learned that when I am fully present with the patient or family, I can move therapeutically with much greater ease. When I am in touch with myself, my feelings, my thoughts with what I see and hear. I am able to make greater contact with the other person.

Essentially in agreement, the POTT perspective puts being "present" this way, that therapists personally, but selectively and purposefully, engage clients according to what each client needs so as to enable therapists to experience their clients consciously as they see them and intuitively as they feel them. It is a deliberate utilization of the personal within the framework and purpose of the therapeutic process. It is a professional use of the personal self to help facilitate the goals of the therapy at conscious and subconscious levels. We are assuming here that this is implied in how Satir articulated the process. However, the POTT perspective emphasizes a structured and systematic training of therapists on how to use their personal themselves strategically within the therapeutic process to potentiate their professional effectiveness by humanizing in an emotionally intimate way their technical tools within the therapeutic relationship

In a study by Kissil and Niño (2011) they propose that "models like POTT, that focus on embracing our vulnerability, can help clinicians be more accepting and caring toward themselves (p. 1)." They then go on to report that in their study:

Forty-nine participants reported changes in their [personal] relationships. They wrote about having an increased ability to be authentic, open, and vulnerable in their [personal] relationships (p. 6).

Obviously, in terms of the goal of person focused training this kind of personal change disposes trainees to being emotionally more open and empathic with their clients and their clients' struggles. This kind of outcome has been reported by various researchers of the POTT training model (Apolinar Claudio \& Watson, 2018; Kissil et al., 2018), as well as personal anecdotal stories from trainees who published on their own personal experience such as Lutz and Irizzary (2009).

\section{The Underlying Philosophy in Practice}

To discuss the conduct of this systematic approach to training therapist's use of the "self" let us illustrate with the underlying philosophy of the Person-of-the-Therapist Training Model:

The POTT model, (without denying the significance of working toward resolution of personal issues), emphasizes the trained conscious, selective and purposeful use of the "self" by the therapist as is in the moment of therapeutic engagement. It does so to the point of stressing consciously working through therapists' own personhood and life experience along with socio-cultural perspectives, but with special emphasis on their emotional and psychological wounds (their signature themes) to be able to empathically relate, understand and access the personal struggles of their clients within their socio-cultural context (Aponte, 1985; Aponte \& Méndez, 2014; Quinn, 2012; Watson, 2019).

Many people are distressed because of a supposition that they suffer emotional dysfunctions because of some characterological vulnerability of theirs, which in a sense we empathize with but only because we operate under the assumption that this deficit is built in in some form or another into each and every person's humanity. These emotional sufferings are universally at the heart of our human journey (Nouwen, 1972). They are challenges integral to the path of our growth to our human potential (Nouwen, 1972, p. 93). The premise is that this common platform of our shared vulnerable humanity lays the foundation for the human component of the therapeutic relationship (empathy) of therapist with client at its deepest level.

The essential goal of the POTT training, which has to be common to all training of all psychotherapists, is to transform aspiring therapists into professionals who can identify personally with their clients while simultaneously professionally observing, analyzing and directing that "self" that is the therapist to manage sensitively and expertly the therapeutic process-personal identification with professional differentiation. In practice this means that while therapists are empathically in their client's shoes, they are also standing outside the therapeutic process (at the core of which is the relationship) as professionals who analyze the encounter and pilot how they work with clients. The aim is to strive to train what Sprenkle and colleagues' term (p. 10) “ 'therapist variables' (characteristics of the therapist that contribute to the [therapeutic] outcome)." 
The POTT model's emphasis on the flawed humanity of therapists has at its roots making it as possible as the individual therapist can do to walk empathically in the shoes of clients-resonating with and caring about clients (Frankl, 1963). To quote Viktor Frankl (1963, p. 176), "Love is the only way to grasp another human being in the innermost core of his personality." For therapists to engage the suffering of their clients, that suffering can only be truly engaged and resonated with, through therapists' own suffering. However, that happens in a healing experience when a therapist "is at home in his own house," (Nouwen, 1972, page 90), that is, at peace with their own wounds, "understood as wounds integral to the human condition," (p. 93) with a life's view that "we can mobilize [these pains] into a common search for life, [so that] those very pains are transformed from expressions of despair into signs of hope," (p. 93). That means viewing them as challenges to stretch ourselves through them to better know ourselves and be able to utilize those pains to motivate ourselves to overcome our own emotional obstacles, and better ourselves. In other words, this work on the self by therapists would have to begin with a commitment to our own journeys toward change and growth, a goal the POTT model shares with so many other approaches to train the use of self.

The goals of POTT training reflect in many ways Carl Roger's "three essential dimensions of the therapist that lead to successful therapy: empathy, positive regard, and congruence" (Sprenkle et al., 2009, p. 20). And I would highlight here that Roger's promoting therapists' "warm acceptance of each aspect of the client's experience," (Sprenkle et al., 2009 , p. 20) must begin with therapists' empathic acceptance of their own human condition. All this leads to itemizing POTT's core five goals which we assume underlies in some form or another all training in the use of self:

- Self-awareness (of past \& current inner experiences)

- In touch with our core issues (signature themes):

- Recognition and acceptance of our flawed humanity

- Ability to access those personal struggles (lapses and triumphs) to resonate with those of clients' journeys

- Ability to utilize those personal aspects of self in service of the therapy's relationship, assessment and interventions within the therapeutic process.

\section{The Training}

How does one accomplish all this? We offer here one example of how this use of "self" training can be carried out. While there are certainly many practical formats for carrying out the objectives of the training, we want to present as examples three basic components of the POTT model around which the training of the self is organized along with one thread that runs throughout the training. The three components are:

1. Getting to know and being in touch with your signature theme (your life's core personal struggle [core issue and derivatives]), meaning an emotional vulnerability that forms your life's challenging issue(s) (Aponte, 2017; Aponte \& Kissil, 2014). This is an issue with its derivatives that makes it possible to empathize with and gain insight into our clients' struggles, and with the challenges they face in overcoming the obstacles those vulnerabilities present to living a healthy and constructive life.

2. Becoming aware in the moment, to the point of familiarity and comfort, of how these personal issues of ours can influence in therapy how we perceive our clients and their issues, how we relate to them, and how we intervene to help them contend with their struggles. The rough parallels of our own life's journeys should give us insight into those of our clients, helping us to be sensitive, resonant and intuitive about what they need from us to trust us, and then to risk change with our help.

3. Developing the facility and skills in the practice of our therapy that are built on our ability to utilize in synch with our technical skill consciously and purposefully our personal insights into ourselves and our humanistic empathy toward others. Our overall purpose is to be able to integrate effectively our "person" with how we work with the technical tools we have learned to utilize in the therapeutic process.

In the Drexel training program where we currently apply this approach, in the first year of student training we dedicate the first of three quarters to working with students in the presence of their cohort on gaining insight into their own vulnerable humanities in the form of identifying the nature and source of their signature themes. In the second quarter we work with them through role plays and observation of their video-taped experiences with clients to achieve selfawareness while engaged with clients therapeutically. In the final third quarter we provide live supervised experiences for each student while they work with a simulated client family or couple, experienced and trained actors hired for this purpose, where the students are guided in the conscious use of themselves toward the personally successful conduct of a clinical session. They not only have the experience with the simulated clients, but they also receive at the end of that session feedback from their "clients" about how they were experienced by the clients in how they related, demonstrated understanding and were therapeutically helpful to them. Throughout this first year of training the threads that pull it all together are the weekly journals they maintain about what they learned from each of their classes, which 
they share with the faculty who provide feedback for each week's journal that is meant to deepen and elaborate what they report.

\section{Touching Both the "Professional" and the "Personal" of the Therapist}

From the very beginning of this training experience the explicit goal has been how to develop the therapeutic potential of the aspiring therapist. The aim has not been the healing of therapists' emotional or familial issues. However, trainees have consistently fed back that the training has also profoundly affected them personally, and then what that has meant to how they develop as therapists (Aponte, 1994b; Kissil et al., 2018).

What follows (with the student's written permission) is what one student wrote after the second quarter where the concentration was on becoming aware of self while conducting therapy.

My signature theme is low self-worth. This can show in my lack of confidence, not feeling good enough, and often feeling unimportant in life. Struggling with depression also plays a role in my low self-worth and I feel that a lot of my negative feelings towards myself come from that. My low self-worth also comes from the dynamic of my relationship with my parents and their lack of support/inability to validate my feelings and experiences. This entire POTT experience has led me to make these observations about myself. At first, I did not realize the extent to which my low self-worth impacts my daily functioning and the way that I go through life. Learning more about myself, my triggers, and my stressors through these presentations has evolved my understanding of my signature theme.

My first experience with an extemporaneous role play was a learning experience for me. It allowed me to better understand exactly how, where, and when my signature theme surfaces in my clinical work. I realized that I tend to close myself off with negative or hostile clients because I begin to feel disliked by them and this makes me uncomfortable. It further decreases my confidence in myself and causes me to pull away or focus on more pleasant clients. I also realized that I tend to avoid conflict because I lack the confidence in myself to feel that I can handle conflict and effectively work with clients through that.

Throughout this quarter, I have really been reflecting on my signature theme and how it impacts my life every day. Specifically, over the course of the past few months, I have noticed how my low self-worth has been inhibiting me from taking certain risks in life and being the person I truly want to be. I have noticed that although I am aware of my signature theme, I still had not been putting in enough effort to work on how I view myself. I have begun to see how due to my low self-worth, I allow others to take care of me and I rely on others for validation. I see how this plays out in both my romantic relationships and my relationship with my parents. During this quarter, I went through a break-up. This break-up process has allowed me to reflect on myself and my signature theme. I have realized that I use relationships as a crutch and a reason to feel good enough, which allows me to avoid doing self-work. When the relationship ends, my self-worth plummets, and I become aware of how damaging it was to allow a relationship to define my self-worth. In order to have a healthy relationship of any type, I must do the work to truly love and accept myself for who I am.

My experiences from this quarter have allowed me to see more clearly how my clinical work can be impacted by my signature theme. I have noticed that I have a fear of rejection due to not always feeling good enough for the client, especially when I cannot gage how well we have joined or do not feel that we have joined. I am learning to not be so reserved in my clinical work, and to use myself and be more assertive with clients. However, I am still finding it difficult to feel confident enough in session to ask certain questions or say certain things when I feel that it may make my client uncomfortable or dislike me. Similar to that, [my] role-play experience has also allowed me to see how I avoid conflict in my clinical work and how I can hold myself back from making progress with clients by doing so. I noticed that I have more difficulty with male clients, and I feel that this is due to my experiences with men throughout my life that have caused me to feel inferior to them. This is something that I must remain aware of in session and work especially hard to overcome. In addition, this quarter I learned that I need to focus more on being present in session and staying in the moment rather than focusing on the solution. I often get so caught up in how I can fix the problem that I forget to meet the client where they are and just listen to what the client is telling me.

What was most striking to us in this student's writeup was how pervasive her newly gained self-awareness was in both her personal life and in her clinical work. And in particular how she was able to so clearly address its impact on how she related to and worked with clients. As noted earlier in this paper, the third quarter would give her a deeper experience in working with life-like clients in the supervised session she had with the actors in the simulated clinical session. The second year of training will provide her with supervision of actual cases she is carrying which will be mostly demonstrated with videotaped segments of clinical encounters. 


\section{Conclusion}

In sum, the personal self has long been recognized as a critical element in the field of psychotherapy, and dealt with in a variety of ways-from a toxic view as in countertransference to a factor that must be worked with to develop a therapist as in gaining differentiation from family, to a factor that should be viewed in both a personal and social perspective to a tool to be purposefully utilized to better relate to and intervene with clients. There is progress in that it has been characterized as a common factor in the therapeutic process. And today there is much emphasis in viewing it as a factor that can and should be utilized actively and purposefully to better relate to clients and understand them and their issues, as well as guide us as therapists in how we can skillfully and sensitively intervene with them. That has challenged us to develop ways of training therapists in the purposeful use of the self within whatever therapy model we choose to guide the therapeutic process. However, I believe that we have made more progress in training for the use of self in relation to the psychology of our clients than we have in how to incorporate the social elements of our living contexts into the philosophy and training techniques we have developed about the use of our personal selves in understanding and utilizing the social elements of our society in how we view the essential nature of the therapeutic process. In conclusion, it seems to me that the training of therapists in the use of self needs to be much further expanded in social perspectives, and further studied and formalized not only in relation to the therapeutic process, but also in our approaches to training therapists so that ultimately it can be formally ensconced as a cornerstone of all psychotherapy training.

Open Access This article is licensed under a Creative Commons Attribution 4.0 International License, which permits use, sharing, adaptation, distribution and reproduction in any medium or format, as long as you give appropriate credit to the original author(s) and the source, provide a link to the Creative Commons licence, and indicate if changes were made. The images or other third party material in this article are included in the article's Creative Commons licence, unless indicated otherwise in a credit line to the material. If material is not included in the article's Creative Commons licence and your intended use is not permitted by statutory regulation or exceeds the permitted use, you will need to obtain permission directly from the copyright holder. To view a copy of this licence, visit http://creativecommons.org/licenses/by/4.0/.

\section{References}

Apolinar Claudio, F. L., \& Watson, M. F. (2018). Perceived impact of the Person of the therapist training model on Drexel University Master of family therapy postgraduates' clinical work. Journal of Family Psychotherapy, 29(1), 58-70. https://doi.org/10.1080/ 08975353.2018.1416236
Aponte, H. J. (1982). The cornerstone of therapy: The person of the therapist. The Family Therapy Networker, 6(2), 19-21.

Aponte, H. J. (1985). The negotiation of values in therapy. Family Process, 24(3), 323-338. https://doi.org/10.1111/j.1545-5300. 1985.00323.X

Aponte, H. J. (1992). Training the person of the therapist in structural family therapy. Journal of Marital and Family Therapy, 18, 269-281.

Aponte, H. J. (1994a). Training of the person of the therapist for work with the Poor and Minorities. In Bread \& Spirit: Therapy with the New Poor. (pp. 147-167). New York and London. W. W. Norton

Aponte, H. J. (1994b). How personal can training get? Journal of Marital and Family Therapy, 20(1), 3-15. https://doi.org/10.1111/j. 1752-0606.1994.tb01007.x

Aponte, H. J. (1996). Political bias, moral values, and spirituality in the training of psychotherapists. Bulletin of the Menninger Clinic, 60, 488-502.

Aponte, H. J. (1998). Love, the spiritual wellspring of forgiveness: An example of spirituality in therapy. Journal of Family Therapy, 20(1), 37-58.

Aponte, H. J. (2002). Spirituality: The heart of therapy. The Journal of Family Psychotherapy, 13, 13-27.

Aponte, H. J. (2017). The philosophy of the person-of-the-therapist training model: The underlying premises. Seminare; Learned Investigations, 38(4), 57-67. https://doi.org/10.21852/sem.2017,4. 05

Aponte, H. J., Powell, F. D., Brooks, S., Watson, M. F., Litzke, C., Lawless, J., \& Johnson, E. (2009). Training the person of the therapist in an academic setting. Journal of Marital and Family Therapy, 35, 38194. https://doi.org/10.1111/j.1752-0606.2009.00123.x

Aponte, H. J., \& Winter, J. E. (1987). The person and practice of the therapist: Treatment and training. Journal of Psychotherapy and the Family, 85-111.

Aponte, H. J., \& Winter, J. E. (2000). The person and practice of the therapist: Treatment and training. In M. Baldwin (Ed.), The use of self in therapy (2nd ed., pp. 127-166). Haworth.

Aponte, H. J., \& Kissil, K. (2014). "If I can grapple with this, I can truly be of use in the therapy room": Using the therapist's own emotional struggles to facilitate effective therapy. Journal of Marital \& Family Therapy, 40(2), 152-164. https://doi.org/10. $1111 /$ jmft.12011

Aponte, H. J., \& Méndez, N. A. (2014). The challenge for the person of the therapist in the work with disadvantaged families. European Journal of Psychology \& Educational Studies., 1(1), 1-9.

Aponte, H. J., \& Kissil, K. (Eds.). (2016). The person of the therapist training model: Mastering the use of self. Routledge.

Aponte, H. J., \& Nelson, G. (2018). I matter, too. Journal of Family Psychotherapy, 29(1), 31-42. https://doi.org/10.1080/08975353. 1018.1416111

Bennett-Levy, J. (2005). What role does the "person of the therapist play" in therapist skill development? Empirical and theoretical perspectives. In M. Jackson \& G. Murphy (eds.), Theory and practice in contemporary Australian cognitive and behaviour therapy: Proceedings of the 28th National AACBT Conference (pp. 32-37). Melbourne: Australian Association for Cognitive and Behavior Therapy.

Blow, A. J., Sprenkle, D. H., \& Davis, S. D. (2007). Is who delivers the treatment more important than the treatment itself? The role of the therapist in common factors. Journal of Marital and Family Therapy, 33(3), 298-317. https://doi.org/10.1111/j. 1752-0606.2007.00029.x

Bochner, D. A. (2000). The therapist's use of self in family therapy. Jason Aronson Inc.

Bowen, M. (1972). Toward a differentiation of a self in one's family. In J. L. Framo (Ed.), Family interaction (pp. 111-173). Springer. 
Cook, J. M., Biyanova, T., Elhai, J., Schnurr, P. P., \& Coyne, J. C. (2010). What do psychotherapists really do in practice? An internet study of over 2000 practitioners. Psychotherapy (chicago, Ill.), 47(2), 260-267. https://doi.org/10.1037/a0019788

D'Aniello, C., \& Fife, S. T. (2020). A 20-year review of common factors research in marriage and family therapy: A mixed methods content analysis. Journal of Marital and Family Therapy, 46(4), $701-718$

Frankl, V. E. (1963). Man's search for meaning. Washington Square Press.

Falicov, C. J. (2009). Commentary: On the wisdom and challenges of culturally attuned treatments for Latinos. Family Process, 48(2), 292-309.

Freud, Sigmund (1964) "Analysis terminable and interminable." In The standard edition of the complete psychological works of Sigmund Freud, edited by James Strachey. Hogarth Press London vol 249

Kissil, K., Carneiro, R., \& Aponte, H. J. (2018). Beyond duality: The relationship between the personal and the professional selves of the therapist in the person of the therapist training. Journal of Family Psychotherapy, 29(1), 71-86. https://doi.org/10.1080/ 08975353.2018.1416244

Kissil, K., \& Niño, A. (2011). Personal gains of MFT trainees following the person-of-the-therapist training (POTT): Is it self-care? A retrospective content analysis American Association for Marriage and Family Therapy. Journal of Marital and Family Therapy. https://doi.org/10.1111/jmft.12213

Lappin, J., \& Hardy, K. (1997). Keeping context in view - the heart of supervision. In C. Storm \& T. Todd (Eds.), The systemic supervisor: context, philosophies, \& pragmatics. Allyn \& Bacon.

McDowell, T., \& Shelton, D. (2002). Valuing ideas of social justice in MFT curricula. Contemporary Family Therapy, 24(2), 313-331. https://doi.org/10.1023/A:1015351408957

Minuchin, S. (2017). The art of creating uncertainty. Psychotherapy Networker, 41(1), 37-38.

Niño, A., Kissil, K., \& Apolinar Claudio, F. L. (2015). Perceived professional gains of master's level students following a person of the therapist training program: A retrospective content analysis. Journal of Marital and Family Therapy, 41(2), 163-176. https:// doi.org/10.1111/jmft.12051

Norcross, J. C., \& Wampold, B. E. (2011). Evidence-Based therapy relationships: Research conclusions and clinical practices. Psychotherapy (chicago, Ill.), 48(1), 98-102. https://doi.org/10.1037/ a0022161
Nouwen, H. J. M. (1972). The wounded healer. Image Books, Doubleday.

Quinn, A. (2012). A person-centered approach to multicultural counseling competence. Journal of Humanistic Psychology., 53(2), 202-251.

Reik, T. (1948). Listening with the third ear. Farrar, Straus and Giroux.

Rogers, C. R. (1961). On becoming a person: A therapist's view of psychotherapy. New York, Houghton Mifflin.

Satir, V. (2000). The therapist story. In M. Baldwin (Ed.), The use of self in therapy (2nd ed., pp. 17-27). Haworth.

Simon, G. M. (2006). The heart of the matter: a proposal for placing the self of the therapist at the center of family therapy research and training. Family Process, 45, 331-344.

Simon, G. M. (2012). The role of the therapist: What effective therapists. Journal of Marital and Family Therapy, 38(s1), 8-12. https://doi.org/10.1111/j.1752-0606.2009.00136.x

Sprenkle, D. H., \& Blow, A. J. (2004a). Common factors and our sacred models. Journal of Marital \& Family Therapy, 30(2), 113-130.

Sprenkle, D. H., \& Blow, A. J. (2004b). Common factors are not islands - They work though models: A response to Sexton, Ridley, and Kleiner. Journal of Marital \& Family Therapy, 30(2), 151-157.

Sprenkle, D. H., Davis, S. D., \& Lebow, J. L. (2009). Common factors in couple and family therapy: The overlooked foundation for effective practice. Guilford Press.

Sude, M. E., \& Gambrel, L. E. (2016). Talking about versus talking with an experiential self of the therapist exercise for family therapy training. Journal of Family Therapy, 00, 00-00. https://doi. org/10.1111/1467-64427.12121

Titchener, E. B. (1909). Lectures of the Experimental Psychology of thought Processes. Macmillan.

Wampold, B. E., \& Imel, Z. E. (2015). The great psychotherapy debate: The evidence for what makes psychotherapy work. Routledge.

Watson, M. F. (2019). Social Justice and Race in the United States: Key issues and challenges for couple and family therapy. Family Process. https://doi.org/10.1111/famp.12427

Publisher's Note Springer Nature remains neutral with regard to jurisdictional claims in published maps and institutional affiliations. 